\title{
Editorial: Dimensions of Experimental Philosophy
}

\author{
Joshua Knobe • Tania Lombrozo • \\ Edouard Machery
}

Published online: 13 June 2010

(C) Springer Science+Business Media B.V. 2010

Psychologists have been borrowing ideas from philosophers for centuries. In a more contemporary development, philosophers have begun to use the methods of experimental psychology and other social sciences to help address philosophical questions. The resulting, cross-disciplinary interchange has been fueled by a new field known as "experimental philosophy." In the first issue of The Review of Philosophy and Psychology dedicated to psychology and experimental philosophy (Machery et al. 2010), we showcased work from philosophers and other cognitive scientists working at the intersection of philosophy and psychology. In this second issue, we bring together another exciting sample of cutting-edge papers that illustrate the breadth, depth, and promise of this interdisciplinary approach.

David Faraci and David Shoemaker take up the question of how people ordinarily make judgments of moral responsibility. They begin by turning to a famous example, widely discussed in the philosophical literature, in which a child is brought up by a heartless dictator and never taught that it is wrong to harm other people. The traditional assumption about this case had been that people would think the child could not properly be held morally responsible for his subsequent actions. Faraci and Shoemaker show that this assumption is mistaken; people are, in fact, quite willing to hold the dictator's son responsible. A systematic experimental study then reveals the surprising ways in which people's judgments in these cases appear to be unaffected by factors that might initially have seemed highly relevant.

\footnotetext{
E. Machery $(\bowtie)$

Department of History and Philosophy of Science, University of Pittsburgh, 1017 CL, Pittsburgh, PA 15260, USA

e-mail: machery@pitt.edu

\section{J. Knobe}

Program in Cognitive Science and Department of Philosophy, Yale University, New Haven, CT, USA e-mail: joshua.knobe@yale.edu
}

T. Lombrozo

Department of Psychology, UC Berkeley, 3210 Tolman Hall, Berkeley, CA 94720, USA

e-mail: lombrozo@berkeley.edu 
Liane Young, Shaun Nichols, and Rebecca Saxe take an experimental approach to a classic conundrum from moral philosophy: so-called "moral luck." A father who leaves a child unattended by a tub will be judged more blameworthy if he returns to find the child (unluckily) drowned than (luckily) safe, despite the fact that the father's actions were identical in both situations. Traditionally, such cases have been taken as evidence that the moral status of an outcome- whether the child drowns or is safe-influences assessments of moral responsibility. Young, Nichols, and Saxe consider an additional factor, namely the status of the agent's beliefs. When the father believes his child will stay put but returns to find him face down in the tub, he had a false belief and experienced a negative outcome. When the father returns to find the child where he left him, he had a true belief and experienced a positive outcome. The father may be judged more blameworthy in the first case not (only) because the outcome was negative, but because his belief was unjustified. In two behavioral and one brain imaging experiment, Young and colleagues find support for this hypothesis about the role of false beliefs in moral luck, raising important new questions for both philosophers and psychologists interested in the nature of moral judgment.

Paulo Sousa and Colin Holbrook likewise consider moral luck, but with the aim of articulating the folk concept of intentional action. In two experiments, they examine whether actions that lead to morally neutral or morally bad outcomes are judged to have been generated "intentionally," and how these judgments are justified. Replicating previous work, they find that an agent's skill in executing an action (e.g. firing a gun at a bull's-eye or a person) impacts judgments of intentional action when the outcome is morally neutral (shooting the bull's-eye) but has a minimal effect when the outcome is morally bad (shooting the person). Through a careful analysis of participants' justification as well as a second experiment, Sousa and Holbrook suggest a novel explanation for these results: that successfully following a plan, rather than skill per se, is critical to one of two concepts of intentional action. Differential reliance on these two concepts can in turn explain the asymmetry between judgments of intentional action for morally neutral versus morally bad outcomes. Sousa and Holbrook's "two concept" proposal promises to spur an already lively debate on the folk concept of intentional action.

In "Folk Psychology, Consciousness, and Context Effects," Adam Arico examines whether and how people are inclined to ascribe conscious mental states, such as anger, pain, feeling upset, etc., to group agents (e.g., corporations, nations, sport teams, etc.). In some exciting new studies, he shows that people's willingness to ascribe conscious mental states depends on the context of the ascription. Ascribing such mental states to a group agent is much more natural when the linguistic context clarifies why the group agent would have a given mental state or when it specifies the object of the mental state (e.g., what the group agent feels upset about). Arico then proposes a general model, "the Agency Model," for the ascription of conscious mental states to agents.

Wesley Buckwalter examines the factors that influence people's intuitions about knowledge. Here he draws on a complex debate within the philosophical literature. This debate starts out with the assumption that people's intuitions about knowledge show a particular sort of pattern; the key question then is about how this pattern of intuitions should be understood and what philosophical implications it might have. 
Buckwalter takes the exact scenarios used within the philosophical literature and shows experimentally that people simply do not have the intuitions they were purported to hold. His paper thereby threatens to undermine the presuppositions of the whole philosophical debate.

William Seeley takes a new approach to the traditional debate between 'observer' and 'participant' accounts in aesthetics. Observer accounts suggest that people approach works of art primarily from an outside, third-person perspective, whereas participant accounts say that people understand artworks by actually simulating the perspective of a character within the work itself. Seeley investigates this issue using an innovative new method. Since people's estimation of distances depends in part on energy expenditure, the participant account should predict that people's estimation of distances within an artwork should depend in part on the energy expenditures that would be required for a character within that artwork itself. An experimental study then shows that distance estimations do indeed show this effect.

In "The Proper Province of Philosophy, Conceptual Analysis and Empirical Investigation," Justin Sytsma discusses Bennett and Hacker's claims that neuroscientists use psychological predicates, such as "seeing" or "detecting edges," improperly when they ascribe mental states to parts of the brain (e.g., when neuroscientists contend that cells in the occipital cortex detect edges) since only whole organisms can have mental states. Sytsma shows on the contrary that lay people have no difficulty ascribing psychological predicates to artifacts. Generalizing from this example, he contends that conceptual analysis should involve an empirical investigation of the proper use of terms.

Some experimental philosophers have used their empirical findings to challenge the use of intuitions in some philosophical areas (e.g., epistemology and the philosophy of language). In "Intuitions, Counter-Examples, and Experimental Philosophy," Max Deutsch argues that these experimental philosophers assume that, in epistemology or in the philosophy of language, philosophical arguments rest on intuitions. Deutsch argues that this assumption is mistaken and that, as a consequence, experimental philosophers' empirical findings do not have any problematic implications for the usual philosophical methods.

Philosophical projects can aim to characterize the nature of our concepts or to characterize the nature of the world. For a philosopher engaged in the latter enterprise - that is, in characterizing the nature of time, knowledge, or causation rather than our concept of time, knowledge, or causation-what role is there for the empirical results of the cognitive sciences? This is the question tackled by Laurie Paul. She argues that contemporary metaphysicians have increasingly focused on characterizing the nature of the world rather than of our concepts, but that empirical data of the kind provided by cognitive science should nonetheless play an important role in metaphysical theorizing. Specifically, Paul argues that metaphysicians engage in a kind of model construction that is constrained by ordinary judgments, but that these ordinary judgments are susceptible to distortions that result from human psychology. Understanding the basis for ordinary judgments can thus serve as an important corrective. Paul illustrates her points with the metaphysics of causation, but the lessons she draws are far-reaching.

The collection of papers brought together in this issue reflects the creativity and growth of experimental philosophy. Philosophers and psychologists are jointly 
contributing to the theoretical and experimental development of this field, with an increasingly large number of topics receiving input from empirical investigation. By generating exciting new work pushing the frontiers of experimental philosophy, and continuing to engage in the critical examination of foundational issues about the relationship between philosophy and psychology, we anticipate a promising future for research at the intersection of psychology and experimental philosophy.

\section{References}

Machery, E., T. Lombrozo, and J. Knobe. 2010. Editorial: Psychology and experimental philosophy. Review of Philosophy and Psychology 1(2): 157-160. 